УДК 004

\title{
РАЗРАБОТКА САЙТА ДЛЯ АНАЛИЗА ФИНАНСОВОЙ УСТОЙЧИВОСТИ ПРЕДПРИЯТИЯ
}

\begin{abstract}
Батукаева Анжела Руслановна старший преподаватель кафедры «Бизнес-информатика»

Вагапова Марьям Вахаевна

студент

ФГБОУ ВО «Чеченский государственный университет»
\end{abstract}

Аннотация. В статье раскрыто понятие финансового анализа. Обоснована значимость автоматизации анализа финансовой устойчивости предприятий. В процессе работы был разработан сайт, предназначенный для автоматизированного расчета анализа финансового состояния предприятий (в данной статье имеется краткий обзор сайта).

Ключевые слова: финансовый анализ, автоматизация, анализ финансовой устойчивости предприятия, финансовое состояние, разработка сайта.

\section{DEVELOPMENT OF A WEBSITE FOR ANALYZING THE FINANCIAL STABILITY OF THE ENTERPRISE}

Batukaeva A.R.
Vagapova M.V.

\begin{abstract}
The article reveals the concept of financial analysis. The importance of automating the analysis of the financial stability of enterprises is substantiated. In the process of work, a website was developed designed for automated calculation of the analysis of the financial condition of enterprises (this article contains a brief overview of the site).
\end{abstract}

Key words: financial analysis, automation, analysis of the financial stability of an enterprise, financial condition, website development.

Финансовый анализ - это часть анализа финансово-хозяйственной деятельности, сущность которого заключается, главным образом, в оценке и 
прогнозировании финансового состояния предприятия [2, с. 53]. Основными целями финансового анализа являются: определение финансового состояния предприятия на определенную дату; выявление изменений его показателей; выявление факторов, которые оказывают влияние на финансовое состояние предприятия; определение направлений изменения финансовой устойчивости.

Одна из важнейших характеристик организации - это ее общее финансовое состояние. Финансовое состояние предприятия - это, в первую очередь, обеспеченность финансовыми ресурсами, денежными средствами, соответствие доходов и расходов [1, с. 158]. То есть перед организациями вопрос ставится следующим образом: «Есть ли у конкретного предприятия возможности для выполнения заявленной им мисси?» Финансовое состояние фирмы имеет большое значения как для самой фирмы (например, для менеджеров и других сотрудников, работающих в ней), так и для других внешних заинтересованных сторон (инвесторы, клиенты организации).

В данной статье показана разработка собственного программного продукта для финансового анализа организаций, основной целью создания которого является автоматизация процесса проведения анализа финансового состояния предприятия [3].

Рассмотрим разработанный сайт - Finance-IT - для анализа финансового состояния предприятия.

На панели меню расположено пять вкладок:

- «Главная» - содержит информацию об инструменте и порядке его работы.

- «Выполнить анализ» - форма для внесения данных об организации, для которой нужно провести анализ (рис. 1).

- «Методика анализа» - включает в себя полное описание принципа анализа и расчета, производимых программой.

- «О нас» - содержит контактную информацию.

- «Вход» - выпадающее меню, которое содержит в себе доступ к формам регистрации и авторизации [4]. 


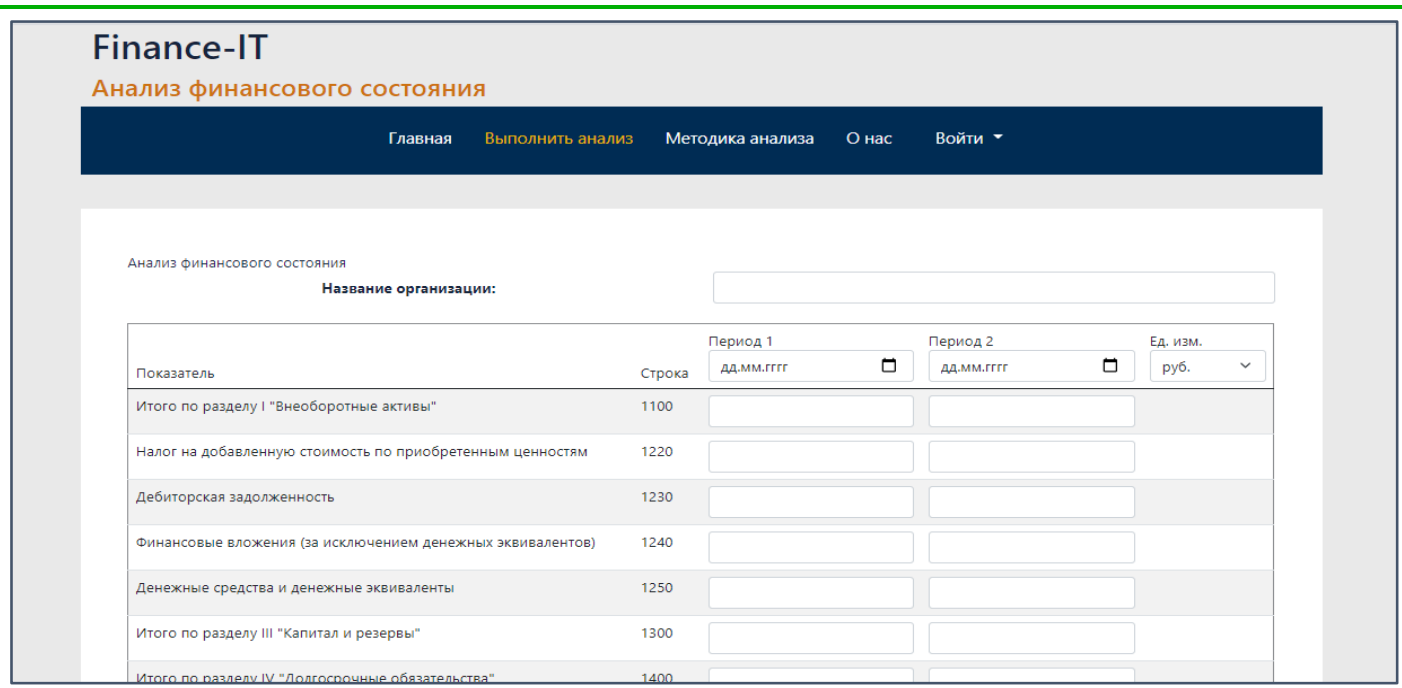

Рис.1. Страница «Выполнить анализ»

Для регистрации пользователю необходимо заполнить 4 поля: имя, email, пароль, подтверждение пароля. Для входа необходимо ввести email и пароль. Личные данные пользователь может поменять в своем личном кабинете (рис. 2).

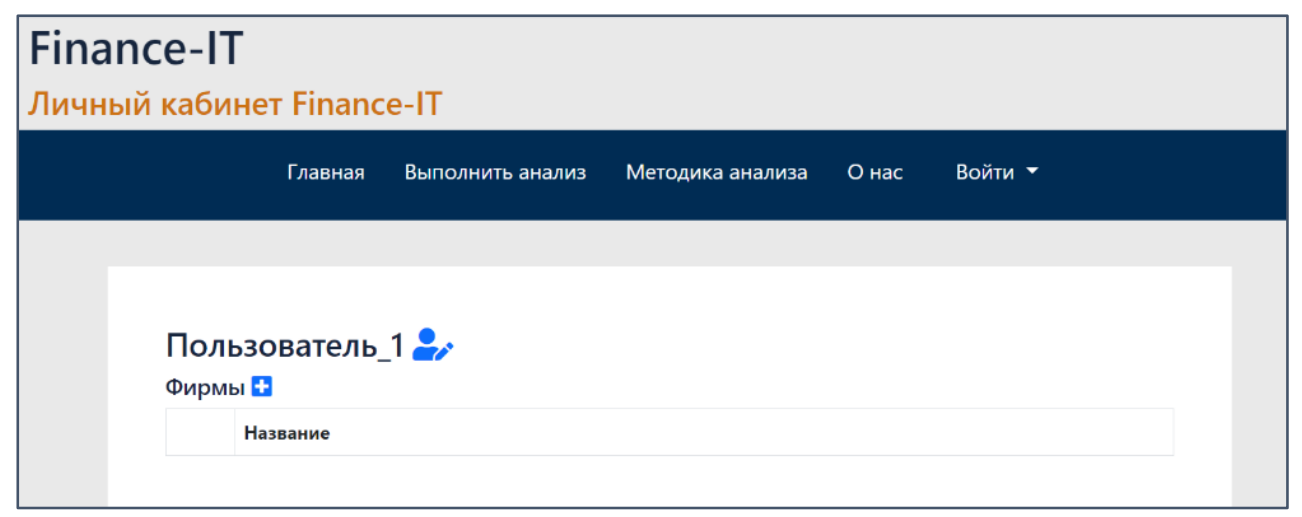

Рис. 2. Личный кабинет пользователя

После аутентификации, в личном кабинете, пользователь может создавать организации, после создания их анализа, он сохранится, доступ к нему будет находиться в строке рядом с названием фирмы (рис.3). 


\section{Finance-IT \\ Личный кабинет Finance-IT}

\section{Главная Выполнить анализ Методика анализа О нас Войти •}

Пользователь_1:

фирмы

Название

亩过 Оирма_1

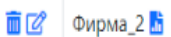

\section{Рис. 3. Список созданных фирм}

Область применения разработки:

- Инвесторы могут использовать в качестве помощника определения направления возможных инвестиций.

- Средние или малые предприятия, предприниматели могут использовать данный продукт:

- для анализа и оценки финансового состояния своего бизнеса;

- для оценки финансового состояния контрагентов и других участников рынка.

Подводя итоги, стоит отметить, что сегодня разработано множество различных инструментов (программ, сайтов, сетевых программ), предназначенных для автоматизации финансового анализа. Несмотря на похожие преследуемые ими цели, такие программные продукты имеют свои отличительные черты. Организации, исходя из своих задач и требований, выбирают решения, которые наиболее точно смогут выполнить необходимые задачи и решить их проблемы.

Одним из решающих факторов финансовой устойчивости и стабильности предприятия являются постоянный контроль за его финансовым положением, оперативное выявление негативных отклонений и принятия взвешенных управленческих решений для их ликвидации. Это возможно только при наличии надежного, удобного и быстрого инструментария для проведения финансового анализа. 


\section{Список литературы}

1. Виноградов М. Н. Анализ финансового состояния предприятия / М. Н. Виноградов, Е. С. Дубровская // Modern Science. 2020. - № 12-4. - С. 5356.

2. Жилкина А.Н. Финансовый анализ: учебник и практикум для вузов / А. Н. Жилкина. - М.: Издательство Юрайт, 2020. - 285 с.

3. Финансовый анализ предприятия [Электронный ресурс] // URL: https://grozny.1cbit.ru/blog/finansovyy-analiz-predpriyatiya/ (дата обращения 27.07.2021г.).

4. Финансовый анализ отчетности предприятия онлайн [Электронный pecypc] // URL: https://www.finalon.com/ru/ (дата обращения 27.07.2021г.)

(C) М.В. Вагапова, А.Р. Батукаева, 2021 